\title{
HIV exposure and related newborn morbidity and mortality in the University Teaching Hospital of Yaoundé, Cameroon
}

\author{
Monebenimp Francisca ${ }^{1,2,8}$, Ella Nga-Essono Dorothee ${ }^{1}$, Zoung-Kany Bissek Anne-Cecile ${ }^{3}$, Chelo David ${ }^{1,3}$, Tetanye Ekoe ${ }^{1}$ \\ ${ }^{1}$ Department of Pediatrics, Faculty of Medicine and Biomedical Sciences, University of Yaounde I, Cameroon, ${ }^{2}$ Neonatology Unit, University \\ Teaching hospital of Yaounde, Cameroon, ${ }^{3}$ Mother and Child Centre of the Chantal BIYA Foundation Yaounde, Cameroon
}

${ }^{8}$ Corresponding author: Monebenimp Francisca, Department of Pediatrics, Faculty of Medicine and Biomedical Sciences, University of Yaounde I, PO Box: 2666 Yaounde, Cameroon

Key words: HIV exposure, newborn, morbidity, mortality, Cameroon

Received: 17/02/2011 - Accepted: 22/03/2011 - Published: 16/04/2011

\begin{abstract}
Introduction: Few studies have established the role of maternal HIV infection on neonatal disease and death. In order to determine whether neonatal morbidity and mortality were associated to maternal HIV infection, a case-control study was conducted in the neonatal unit of the University Teaching Hospital of Yaoundé from July 2006 to December 2007. Methods: Babies born from HIV positive mothers were recruited as cases. For each case, two babies born from HIV negative mothers were selected as controls. Informed verbal consent was obtained from the mother before inclusion of the newborn in the study. Information on demographics, history of pregnancy, diseases and outcome of the newborns were extracted from patients' files. The distribution of these parameters between cases and control was analyzed using chi-square. Association of demographics, clinical and paraclinical parameters with mortality was explored using univariate analysis and logistic regression. Data were analyzed using Epi Info version 3.5.1 Windows. Results: Out of 240 newborns enrolled, 80 were cases and were 160 controls. The mean age of cases was $1.69 \pm 2.73$ days compared to $1.46 \pm 2.36$ days for controls $(p=0.26)$. Cases significantly differed from controls on mother's marital status $(p=0.02)$, level of education $(p<0.001)$, number of prenatal consultations $(p<0.001)$, anemia chemoprophylaxis ( $p=0.01)$ and drug abuse $(p<0.001)$. Cases and controls were similar for prematurity, respiratory distress, sepsis, meningitis and urinary tract infection. The death rate was identical in both groups $(p=0.52)$. Using Univariate analysis, risk factors associated to mortality in both groups were prematurity $(p<0.001)$ and low birth weight $(p<0.001)$. Conclusion: This study showed no statistical difference in morbidity and mortality between newborns from HIV positive and HIV negative mothers.
\end{abstract}

Pan African Medical Journal. 2011; 8:43

This article is available online at: http://www.panafrican-med-journal.com/content/article/8/43/full/

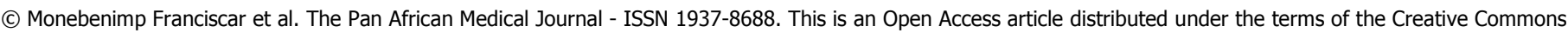

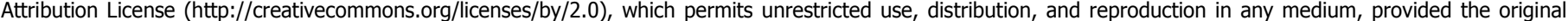
work is properly cited. 
In Africa, HIV infection rates among pregnant women ranged from 15 to 40 percent in countries with the highest overall HIV prevalence in 2006 [1]. Even though HIV is not a direct cause of neonatal death, maternal HIV status affects newborn survival by causing an increased risk of stillbirth and death in the neonatal period and infancy; this increase risk extend to those babies who do not become HIV positive [2]. The interaction of HIV with other infections and the indirect effects of HIV, such as poverty and maternal illness, contribute to the poor outcome of these newborns. It has been established that newborns exposed to mother's HIV infection have a higher mortality rate than those not exposed [3-5]. HIV is more prevalent in Cameroon, and the pattern of HIV epidemic is changing overtime with a prevalence in the general population that went from 5.5 in 2001 to 5.3 in 2009 [2]. Women attending antenatal visits are more aware of being tested for HIV infection. The rate of HIV testing acceptance during pregnancy went from $31 \%$ in $2005,77.7 \%$ in 2007 to $83.4 \%$ in 2009 [6]. To answer the question whether maternal HIV infection is associated to newborn's morbidity and mortality in our setting, we performed a hospital based study, with the aim of addressing the issue of building a comprehensive communicative approach in antenatal care (ANC) clinic for the prevention of mother-to-child transmission of HIV.

\section{Methods}

This was a case control study carried out at the neonatology Unit of the University Teaching Hospital of Yaoundé (UTHY) from July 2006 to December 2007. The UTHY is a referral hospital that had a 5 bedded labor room. The staff of the maternity comprises 7 gynecologists /obstetricians, 9 residents and 18 nurses including 2 midwives. Cases included in the study were newborns from mothers with known HIV positive serology, born in the maternity of the UTHY and admitted in the neonatal unit of the same hospital. Newborns from HIV negative mothers, born in the same hospital and admitted in the same neonatal unit were taken as controls. Newborns with life threatening congenital anomalies were excluded from the study because of the potential interaction with morbidity and mortality.

Since 2005 , the hospital policy to prevent mother-to-child transmission of HIV is to admit in the neonatal unit all baby from HIV positive mothers, free of charges, for up to 72 hours. The aim of this policy is to insure that mothers understand the administration of antiretroviral drugs and the feeding option of the newborn while assuring psychosocial support to the parents. The package for HIV positive pregnant women included antiretroviral (ARV) drugs such as the combined tablets of Zidovudine and Lamivudine at 300/150 mg every 12 hours starting at 28 weeks of pregnancy and a tablet of Nevirapine $200 \mathrm{mg}$ at onset of labor. Newborns receive Zidovudine $4 \mathrm{mg} / \mathrm{kg} / \mathrm{day}$ every 12 hours for 4 weeks and a single dose of Nevirapine $2 \mathrm{mg} / \mathrm{kg}$ within 72 hours of delivery.

Informed verbal consent was obtained from mothers before enrolment in the study. Ethical clearance was obtained from the National Ethical Committee.

The selection of cases was as followed: babies born from an HIV positive mother were randomly selected from the neonatology patient register. In order to increase the power of the study, for each case, two babies born from HIV negative mothers were selected as controls. This was done until fulfillment of the calculated sample size, taking into account a proportion of $15 \%$ of HIV infected newborns.

Information was extracted from mothers' files regarding history of pregnancy and delivery and other relevant demographics. Information collected from the newborn files included age and sex of the baby, anthropometric parameters, glycemia, calcemia, infection and other clinical problems presented during the length of stay in hospital. Neonatal sepsis, meningitis and urinary tract infection were validated when bacteria were isolated respectively in the culture of blood, central nervous system fluid and urine. Data were analyzed using Epi Info version 3.5.1 Windows. No matching criterion was used in the analysis. The Chi square test was performed to compare proportions and the level of significance was set at 0.05 . Variables significantly associated with mortality at a level of $p<0.07$ on the univariate analysis and those variables that we thought could be associated with mortality in a fishing expedition were further put in a logistic regression model to identify independent risk factors. The assumption was made for a protective effect of malaria chemoprophylaxis.

\section{Results}

A total of 240 newborns were enrolled in the study. A male newborn with spina bifida and a female with omphalocele were excluded from the study. Out of the 80 newborns from HIV-positive mothers, 42 (52.5\%) were males and $38(47.5 \%)$ females. In the group of newborns from HIVnegative mothers, $85(53.1 \%)$ were males and $75(46.9 \%)$ females $(\mathrm{p}=0.07)$. The age range of the study population varied from birth to 13 days. The more represented age range was from 2 to 4 days, $28(35 \%)$ cases compared to $77(48.1 \%)$ controls. The mean age in the case group was $2.13 \pm 3.34$ days compared to $1.46 \pm 2.36$ days for controls $(p=0.26)$.

Table 1 shows the demographic features and antenatal characteristics of HIV-positive and HIV-negative mothers. HIV positive mothers, 46 $(57.5 \%)$ were more likely to attend UTHY ANC than HIV negative mothers $(n=70,43.8 \%, p=0.03)$. The mean maternal ages between HIV positive and HIV negative mothers was comparable, $27.97 \pm 4.86$ years in cases and $26.99 \pm 5.34$ years in controls $(p=0.10)$. Most of the mothers in the case group were single $47(58.8 \%)$ and multiparous $60(75 \%)$ while in the control group most of them were respectively married 89 (56.6\%) $(p=0.02)$ and $101(63.1 \%)$ were multiparous $(p=0.39)$. As far as education was concerned, the majority of mothers of the study population was at college level, $48(60 \%)$ for cases and $118(73.8 \%)$ for controls $(p<0.001)$. Drug abuse was reported by 6 mothers in the HIV positive group compared to 1 mother in the HIV negative group $(p<0.001)$. Alcohol was reported by 4 and heavy tobacco smoking by 2 HIV positive mothers; one HIV negative mother reported alcohol consumption. Malaria chemoprophylaxis during pregnancy was noted in 71 cases (88.8\%) compared to 148 controls $(93.1 \%)(p<0.18)$ but for anemia chemoprophylaxis $73(91.2 \%)$ of HIV positive mothers received ion and folate tablets against 157 $(98.1 \%)$ in the group of HIV negative mothers $(p=0.01)$. Malaria in pregnancy was observed in $19(23.8 \%)$ cases and $17(10.6 \%)$ controls $(p<0.001)$. HIV-positive women who received antiretroviral therapy on the basis of their lymphocytes count were $74(92.5 \%)$ in number and 11 
(14.8\%) were put on tritherapy throughout pregnancy; $36(48.6 \%)$ were on Zidovudine during pregnancy plus Nevirapine at onset of labor while $17(22.9 \%)$ had Combivir without Nevirapine at onset of labor and $10(13.5 \%)$ had Nevirapine alone at onset of labor.

HIV testing was done and obtained at labor for 6 HIV positive mothers. These women did not receive ARV but their offspring had Nevirapine and Zidovudine as the other newborns. Looking at t history of delivery, premature rupture of membranes was noticed in 25 cases (31.3\%) compared to $75(46.9 \%)$ controls $(p=0.01)$. Most of the newborns were delivered vaginally, $63(78.8 \%)$ in HIV exposed babies and $115(71.9 \%)$ in newborns from HIV negative mothers. The difference was not statistically significant $(p=0.13)$. Premature deliveries were $22(27.5 \%)$ in cases compared to $34(21.9 \%)$ in controls $(p=0.41)$. The mean weight in HIV exposed newborns was $2950 \pm 579 \mathrm{~g}$ while it was $2969 \pm 748 \mathrm{~g}$ for controls $(p=0.9)$. The mean height was $48.43 \pm 2.66 \mathrm{~cm}$ for cases compared to $48.92 \pm 3.76 \mathrm{~cm}$ for controls $(=0.14)$.

Table 2 illustrates morbidity and mortality profile of the newborns from HIV positive and HIV negative mothers. The number of newborns in the case group with an Apgar score below 6 at 5 minutes was $14(17 \%)$ compared to $53(33.1 \%)$ in the control group p<0.001). There was no statistically significant difference between the newborns from HIV positive mothers and those from HIV negative mothers as concerns low birth weight $(p=0.53)$, body temperature $(p=0.30)$, metabolic disorders such as hypoglycemia $(p=039)$ and hypocalcemia ( $p=0.77)$ and neonatal infection, septicemia $(p=053)$, meningitis $(p=0.44)$, urinary tract infection $(p=031)$. Among the cases, $14(17.5 \%)$ were on breastfeeding while 154 $(96.3 \%)$ controls were on the same choice of feeding $(p<0.001)$. The length of stay in hospital was comparable in both groups $9.1 \pm 8.3$ days for cases against $8.8 \pm 8.6$ days for controls $(p=0.57)$.

The number of death in cases was $8(10 \%)$ compared to $15(9.4 \%)$ in controls and the difference between the two groups was not statistically significant $(p=0.52)$. The univariate analysis for mortality in table 3 shows that factors associated with mortality were prematurity $(O R=3.6 ; 95 \%$ $\mathrm{CI}=1.47-8.87 ; \mathrm{p}=0.006)$ and low birth weight $(\mathrm{OR}=3.31 ; 95 \% \mathrm{CI}=1.3-8.09 ; \mathrm{p}=0.009)$. None of the covariates studied was associated with neonatal mortality in the logistic regression model performed.

\section{Discussion}

The study sample represented (8.3\%) of the 956 HIV exposed and (7.6\%) of the 2103 non-HIV exposed newborns delivered in the UTH maternity from July 2006 to December 2007. In this study, HIV positive mothers had a low level of education and were more likely to be single compared to HIV negative mothers as shown in Zambia and Rwanda $[7,9,10]$. The two groups of mothers were comparable as regards to age and income generating activities as shown in a previous study in Cameroon [11].

\section{Prenatal and delivery history}

The majority of HIV positive and HIV negative mothers fulfilled the World Health Organization requirements of at least 4 ANC during pregnancy $[12,13]$. The number of antenatal consultations was similar in both groups of mothers; though a higher proportion of HIV positive mothers had on average 4 ANC visits more than HIV negative mothers. In addition, HIV positive mothers were more likely to come to ANC visits at the UTHY probably because of their related medical problems, as observed with the higher proportion of malaria in pregnancy. This disease was highly noticed in a study in Malawi [14] where the prevalence of malaria in HIV positive mothers reached (56.3\%) compared to (36.5\%) for HIV negative mothers. The discrepancy could be explained by the fact that our study population was urban in majority; in addition, a high proportion of women received malaria prophylaxis (88.8\% of HIV positive mothers and $92.5 \%$ of the HIV negative mothers). Iron deficiency anemia is the most common cause of anemia in pregnancy. The rate of malaria prophylaxis in this study was considerable and the majority of women had the required number of ANC visits; we can therefore presume that these women received nutritional counseling, iron and folic acid for anemia prophylaxis. Theses interventions are important in reducing anemia in pregnancy [13] and might explain why we did not find a single case of anemia in our study.

\section{Neonates morbidity and mortality}

The majority of newborns were males in the two groups but the difference was not statistically significant as pointed out by some authors [15,16]. The prevalence of prematurity was high in the two groups and the difference was not statistically significant. This was in accordance with the findings of Lepage et al [7]. Temmerman et al noticed a significant difference, $21.1 \%$ in the group of HIV infected mothers compared to $9.4 \%$ in HIV negative mothers [2] but, in this study, mothers were recruited as cases on the basis of having a low birth weight that could bias the result towards prematurity. Further, Haeri et al found that prematurity was more common among HIV-positive women than uninfected women (OR $=2.27,95 \% \mathrm{CI}=1.22-4.25$ ) [17] but mothers were more likely to have heavy tobacco smoking and cocaine use. Neonatal asphyxia was high among cases compared to controls. This finding could be explained by the fact that the controls were newborns hospitalized in the neonatal unit because of birth trauma as this was a major reason for admission. The number of low birth weights was not statistically different between neonates born from HIV positive and HIV negative mothers. This finding does not concord with Ezeaka et al in Nigeria [18] who found that there were three times more low birth weights in the HIV positive mothers than in the HIV uninfected mothers $(\mathrm{OR}=3.47 ; 95 \mathrm{CI}=1.69-7.27 ; \mathrm{P}=0.0003)$. The mean weight of newborns was similar in both groups. This was contrary to other studies which found that newborns exposed to HIV were more likely to have low birth weights $[2,7]$. Considering the adequate numbers of antenatal care we could assume that infected women were well managed during pregnancy, and the fact that they took antiretroviral therapy early enough, before the third trimester of pregnancy, could explain why the difference of mean weight was not statistically significant. These findings are similar to those of other authors who showed that anthropometric measurements of infants born from asymptomatic HIV infected mothers are comparable to those in the general population in contrast to children of drug-addicted mothers [19] in our study, there was only one HIV negative mother that was drug-addicted. Neonatal mortality was similar in the two groups, as found in other studies in Rwanda, Malawi, Zambia and Tanzania [7,8] . Neonatal death rates were 94 per 1000 in HIV exposed babies compared to 100 per 1000 on controls. These figures were high compared to the 40 per 1000 reported at national 
level [20]. The explanation could reside on the fact that this is a referral hospital and many of the deliveries were conducted in women who were not managed during pregnancy in this hospital and who came late, the high level of birth asphyxia found being part of this delay.

Factors associated with mortality in the univariate analysis were prematurity and low birth weight even though these and other variables analyzed did not appear as risk factors for mortality in a logistic regression model. However, some authors have shown that prematurity and low birth weight were considerably associated to morbidity and mortality in the neonatal period as well as in the first year of life [21-23] and that there was a direct correlation between vertical transmission of HIV, low birth weight and high mortality [23-26].

This study has a limitation that it could not tell strongly the number of mothers on ARV therapy that was symptomatic and their biological profiles. So there is a need to address this issue in further studies as misclassification bias might lead to the failure to pick up a difference, if any, between the two groups of neonates as far as prematurity, low birth weight and mean birth weight are concerned. Taking into consideration the variables that showed a trend to significance, the sample size was small enough to pick up differences between newborns from HIV positive and HIV negative mothers. A bias could have been introduced because of the choice of controls as they were more likely to have neonatal asphyxia that was the primary reason for admission in the neonatal unit. This was a hospital based study which did not cover the overall neonatal period; therefore these results could not be generalized to the community.

\section{Conclusion}

This case control study showed that mortality rate was similar in newborns from HIV positive mothers and HIV negative mothers. Prematurity and low birth weight were potential risk factors for mortality in the univariate analysis but failed to be demonstrative in a logistic regression model. The impact of maternal HIV infection might not be evident in the neonatal period. Further studies are in progress and will take into account HIV positive mothers' clinical and biological stages. However, health professionals should be aware of and properly address the issue of prematurity and low birth weight when taking care of HIV-positive pregnant women.

\section{Competing interests}

The authors declare no competing interests.

\section{Authors' contribution}

ICMJE authorship criteria met. All the authors have read and approve the final version of the manuscript.

\section{Acknowledgements}

Acknowledgments addressed to the neonatal and maternity staff of the University teaching Hospital of Yaoundé for their collaboration in conducting this study.

Tables

Table 1: Sociodemographic and Antenatal characteristics of HIV- positive and HIV-negative mothers of the newborns, University Teaching Hospital, July 2006-December 2007

Table 2: Morbidity and mortality profile of the neonates born from HIV- positive mothers and HIV-negative mothers, University Teaching Hospital, July 2006-December 2007

Table 3: Univariate analysis and logistic regression of risk factors for mortality in neonates born from HIV-positive and HIV-negative mothers, University Teaching Hospital, July 2006-December 2007

\section{References}

1. UNAIDS. report on the global AIDS epidemic, 2006, Geneva. Joint United Nations programme on HIV/AIDS (UNAIDS)

2. Temmerman $\mathrm{M}$, Plumer FA, Mirza NB, Ndinya-Achola JO, Wamola IA, Nagelkerke $\mathrm{N}$ et al. Infection with HIV as a risk factor for adverse obstetrical outcome. AIDS. 1990; 4 (11):1087-1093. This article on PubMed

3. Newell ML, Branhmbhatt $H$, Ghys P. Child mortality and HIV infection in Africa: a review. AIDS. 2004 Jun;18 Suppl 2:S27-34. This article on PubMed

4. OMS/FISE/2006. Statistiques de mortalité OMS: Statut sanitaire. Documents communs OMS/FISE. Genève/2006 
5. UNICEF. Les enfants et le SIDA: un désastre imminent; les répercussions croissantes de l'infection à VIH sur les femmes, les enfants et la vie familiale dans le monde en développement. Genève $1990: 6-8$

6. Ministère de la Santé Publique/Comité national de lutte conte le SIDA. Rapport d'évaluation du plan stratégique national de lutte contre le VIH/SIDA au Cameroun (2006-2010). Draft1, Juin 2010.

7. Lepage P, Dabis F, Hitimana DG, Msellati P, Van Goethem C, Stevens AM et al. Perinatal transmission of HIV-1: lack of impact of maternal HIV infection on characteristics of live births and on neonatal mortality in Kigali, Rwanda. AIDS. 1991; 5:295-300. This article on PubMed

8. Chilongozi D, Wang L, Brown L, Taha T, Megan V, Emel L et al. Morbidity and mortality among a cohort of human immunodeficiency virus type-1 infected and non infected pregnant women and their infants from Malawi, Zambia and Tanzania. Pediatr Infect Dis J. 2008; 27(9): 808-814. This article on PubMed

9. Hira SK, Kamanga J, Bhat GJ, Mwale C, Tembo G, Luo N et al. Perinatal transmission of HIV-1 in Zambia. BMJ. 1989; 299:1250-1252. This article on PubMed

10. Njanjo Ekobe GS. Etude épidémiologique de la transmission materno-foetale du VIH chez les femmes enceintes à la maternité du centre hospitalier et universitaire de Yaoundé. Thèse de doctorat en médecine, Université de Yaoundé I, Cameroun, 2005

11. Kouam L, Nsangou I, Mbanya D, Nkam M, Kongnyuy E, Ngassa et al. Prevention of mother-to-child transmission of HIV in Cameroon: experiences from the University Teaching Hospital in Yaoundé (Cameroon). Zentralbl Gynakol. 2006; 128:82-86. This article on PubMed

12. Ketsela T, Habimana $P$, Martines J, Mbewe A, Abimbola W, Nsungwa $S$, et al. Prise en charge intégrée des maladies de l'enfance (PECIME), dans donnons sa chance à chaque nouveau-né de l'Afrique. UNFPA, UNICEF, USAID, WHO 2006 Juin ; $5: 94-100$

13. 13. USAID: Access. Soins prénatals focalises: fournir des soins intégrés, individualisés au cours de la grossesse. février 2007 http://pdf.usaid.gov/pdf_docs/PNADK397.pdf. Accessed April April 12010

14. Verhoeff F, Brabin B, Hart C, Chimsuku L, Kazembe P, Broadhead R, et al. Increased prevalence of malaria in HIV infected pregnant woman and its implication for malaria control. Trop Med Int Health. 1999; 4(1): 5-12. This article on PubMed

15. Eloundou Odi EB. Etiologies et facteurs aggravant la morbidité et la mortalité néonatale à I'hôpital Gynéco-Obstétrique et Pédiatrique de Yaoundé. Thèse de doctorat en médecine. Université de Yaoundé I 2007

16. Mutombo T. Mortalité néonatale dans un hôpital rural, cas de l'hôpital protestant de Dabou (Côte d'Ivoire). Méd Afr Noire. 1993; 40(7): $471-477$

17. Haeri S, Shauer M, Dale M, Leslie J, Baker AM, Saddlemire S, Boggess K. Obstetric and newborn infant outcomes in human immunodeficiency virus-infected women who receive highly active antiretroviral therapy. Am J Obstet Gynecol. 2009 Sep;201(3):315.e15. This article on PubMed

18. Ezeaka VC, Iroha EO, Akinsulie AO, Temiye EO, Adetifa I. Anthropometric indices of infants born to HIV-1-infected mothers: a prospective cohort study in Lagos, Nigeria. Int J STD AIDS. 2009; 20(8): 545-8. This article on PubMed

19. Blanche S, Rouzioux C, Moscato ML, Veber F, Mayaux MJ, Jacomet et al. A prospective study of infants born to women seropositive for human immunodeficiency virus type 1 - HIV infection in newborn French collaborative study group. N Engl J Med. 1989; 320(25): 16431648. This article on PubMed

20. 20. Institut National de la Statistique (INS) et ORC Macro 2004. Enquête démographique et de santé du Cameroun 2004. Juin 2005 www.measuredhs.com/pubs/fr163/fr163-cm04.pdf. Accessed April 12010

21. Monebenimp F, Thio R, Nana AD. Morbidité et mortalité des naissances intra hospitalières du CHU de Yaoundé, Cameroun. Clin Mother Child Health. $2005 ; 2(2): 355-358$

22. McCormick MC. The contributors of low birth weight to infants mortality and childhood morbidity. N Engl J Med. 1985 Jan 10;312(2):8290. This article on PubMed

23. Chase HC. Infant mortality and weight at birth: 1960 United States birth cohort. Am J Public Health Nations Health. 1969; 59: 16181628. This article on PubMed

24. Lepage P, Msellati P, Van de Perre P, Hitimana DG, Dabis F. Characteristics of newborns and HIV-1 infection in Rwanda 1992 . AIDS. 1992 Aug;6(8):882-3. This article on PubMed

25. Nair P, Alger L, Hiness S, Seiden S, Hebel R, Johnson JP. Maternal and neonatal characteristics associated with HIV infection in infant of seropositive women. J Acquir Immune Defic Syndr. 1993 Mar;6(3):298-302. This article on PubMed 
26. Taha TE, Dallabetta GA, Canner JK, Chiphangwi JD, Liomba G, Hoover DR et al. The effect of human immunodeficiency infection on birth weight and infant and child mortality in urban Malawi. Int J Epidemiol. 1995; 24(5): 1022-1029. This article on PubMed

Table 1: Sociodemographic and Antenatal characteristics of HIV- positive and HIV-negative mothers of the newborns, University Teaching Hospital, July 2006-December 2007

\begin{tabular}{|c|c|c|c|}
\hline Variable & $\begin{array}{c}\text { HIV+ mothers } \\
\mathbf{n}=\mathbf{8 0}\end{array}$ & $\begin{array}{l}\text { HIV- mothers } \\
\quad n=160\end{array}$ & P value \\
\hline \multicolumn{4}{|l|}{ Demographics } \\
\hline Mean age of the mothers (years) & $27.32 \pm 5.20$ & $26.99 \pm 5.34$ & 0.10 \\
\hline Married mothers ( $\mathrm{n} \%$ ) & $33(41.3)$ & $89(55.6)$ & 0.02 \\
\hline College level of education ( $n$ \%) & $48(60)$ & $118(73.8)$ & $<0.001$ \\
\hline Income activity generating ( $\mathrm{n} \%$ ) & $40(50)$ & $63(39.4)$ & 0.07 \\
\hline \multicolumn{4}{|l|}{ History of pregnancy and delivery } \\
\hline Multiparity (n \%) & $64(80)$ & $120(75)$ & 0.39 \\
\hline Drug abuse (n \%) & $6(7.5)$ & $1(0.6)$ & $<0.001$ \\
\hline UTHY site of ANC & $46(57.5)$ & $70(43.8)$ & 0.03 \\
\hline At least 4 ANC (n \%) & $70(87.5)$ & $117(73.1)$ & $<0.001$ \\
\hline Malaria in pregnancy $(\mathrm{n} \%)$ & $19(23.8)$ & $17(10.6)$ & $<0.001$ \\
\hline Anemia in pregnancy $(\mathrm{n} \%)$ & 0 & 0 & \\
\hline Syphilis (n \%) & $1(1.3)$ & $3(1.9)$ & 0.58 \\
\hline Malaria chemoprophylaxis (n \%) & $71(88.8)$ & $148(92.5)$ & 0.18 \\
\hline Anemia chemoprophylaxis ( $\mathrm{n} \%$ ) & $73(91.3)$ & $157(98.1)$ & 0.01 \\
\hline Gestational age $\leq 37$ weeks $(n \%)$ & $22(27.5)$ & 35 (21.9) & 0.41 \\
\hline Normal delivery ( $\mathrm{n} \%$ ) & $63(78.8)$ & $115(71.9$ & 0.13 \\
\hline Premature rupture of membranes ( $\mathrm{n} \%$ ) & $25(31.3)$ & 75 (46.9) & 0.01 \\
\hline Choice of breastfeeding & $14(17.5)$ & $154(96.3)$ & $<0.001$ \\
\hline
\end{tabular}

UTHY: University Teaching Hospital of Yaoundé 
Table 2: Morbidity and mortality profile of the neonates born from HIV- positive mothers and HIV-negative mothers, University Teaching Hospital, July 2006-December 2007

\begin{tabular}{|c|c|c|c|}
\hline variable & $\begin{array}{c}\text { Newborns from HIV+ } \\
\text { mothers } \\
\mathbf{n}=\mathbf{8 0}\end{array}$ & $\begin{array}{c}\text { Newborns from } \\
\text { HIV- mothers } \\
n=160\end{array}$ & P value \\
\hline Neonatal asphyxia ( $\mathrm{n} \%)$ & $14(17.5)$ & $53(33.1)$ & $<0.001$ \\
\hline Low birth weight ( $\mathrm{n} \%$ ) & $16(20)$ & $35(21.8)$ & 0.53 \\
\hline Mean birth weight $(\mathrm{g})$ & $2950 \pm 578$ & $2969 \pm 748$ & 0.90 \\
\hline Mean height $(\mathrm{cm})$ & $48.43 \pm 2.66$ & $48.92 \pm 3.76$ & 0.14 \\
\hline Hypothermia ( $\mathrm{n} \%$ ) & $23(28.8)$ & $61(38.1)$ & 0.30 \\
\hline Hypoglycemia ( $\mathrm{n} \%$ ) & $10(12.5))$ & $17(10.6)$ & 0.39 \\
\hline Hypocalcaemia (n \%) & $9(11.3)$ & $20(12.5)$ & 0.77 \\
\hline Neonatal sepsis ( $\mathrm{n} \%)$ & $9(11.3)$ & $19(11.9)$ & 0.53 \\
\hline Neonatal meningitis ( $\mathrm{n} \%$ ) & $4(5.0)$ & $6(3.8)$ & 0.44 \\
\hline Neonatal respiratory distress ( $\mathrm{n} \%$ ) & $12(15)$ & $20(12.5)$ & 0.36 \\
\hline Urinary tract infection ( $\mathrm{n} \%$ ) & $3(3.8)$ & $3(1.9)$ & 0.31 \\
\hline Neonatal jaundice ( $\mathrm{n} \%)$ & $21(26.3)$ & $42(26.3)$ & 0.55 \\
\hline Mean length of stay in hospital (days) & $9.1 \pm 8.3$ & $8.8 \pm 8.6$ & 0.57 \\
\hline Neonatal death (n \%) & $8(10)$ & $15(9.4)$ & 0.52 \\
\hline
\end{tabular}


Table 3: Univariate analysis and logistic regression of risk factors for mortality in neonates born from HIV-positive and HIV-negative mothers, University Teaching Hospital, July 2006-December 2007

\begin{tabular}{|c|c|c|c|c|c|}
\hline Variables & $\begin{array}{c}\text { Newborns from } \\
\text { HIV+ mothers } \\
\text { n(\%) }\end{array}$ & $\begin{array}{c}\text { Newborns } \\
\text { from HIV- } \\
\text { mothers } \\
n(\%)\end{array}$ & $\overline{O R}$ & CI (95\%) & P value \\
\hline \multicolumn{6}{|l|}{ Univariate analysis } \\
\hline Income generating activity & $4(10)$ & $6(9.5)$ & 1.02 & $0.43-2.44$ & 0.48 \\
\hline Malaria in pregnancy & $1(5.3)$ & $1(5.9)$ & 0.51 & $0.11-2.28$ & 0.28 \\
\hline At least 4 ANC & $7(10)$ & $10(8.5)$ & 1.30 & $0.47-3.56$ & 0.38 \\
\hline Malaria chemoprophylaxis & $8(11.3)$ & $12(8.1)$ & 0.58 & $0.16-2.12$ & 0.30 \\
\hline Premature rupture of membranes & $2(8.0)$ & $7(9.3)$ & 0.89 & $0.36-2.19$ & 0.49 \\
\hline Prematurity & $4(25)$ & $6(18.8)$ & 3.6 & $1.47-8.87$ & 0.006 \\
\hline Low birth weight $<2500 \mathrm{~g}$ & $3(18.8)$ & $7(20)$ & 3.31 & $1.3-8.09$ & 0.009 \\
\hline Neonatal sepsis & $0(0)$ & $2(10.5)$ & 0.70 & $0.15-3.15$ & 0.48 \\
\hline Neonatal meningitis & $1(25)$ & $0(0)$ & 1.04 & $0.12-8.6$ & 0.64 \\
\hline Neonatal respiratory distress & $4(33.3)$ & $6(30)$ & 2.76 & $0.51-14.82$ & 0.20 \\
\hline Anemia & $0(0)$ & $2(40)$ & 2.38 & $0.4-11.70$ & 0.25 \\
\hline \multicolumn{6}{|l|}{ Multivariate analysis } \\
\hline Prematurity & - & - & 5.69 & $(0.74-43.54)$ & 0.09 \\
\hline Low birth weight & - & - & 2.54 & $(0.33-19.34)$ & 0.36 \\
\hline Malaria chemoprophylaxis & - & - & 3.92 & $(0.77-19.79)$ & 0.09 \\
\hline Premature rupture of membranes & - & - & 0.88 & $(0.25-3.06)$ & 0.84 \\
\hline Malaria in pregnancy & - & - & 0.65 & $(0.07-5.66)$ & 0.70 \\
\hline At least 4 ANC & - & - & 1.06 & $(0.30-3.75)$ & 0.91 \\
\hline
\end{tabular}

